\title{
A relação entre o discurso didático científico e o discurso jornalístico na revista Recreio
}

\author{
Thaís Helena Furtado \\ Sabrina Franzoni
}

Resumo: Este estudo tem como objeto a Recreio, revista semanal direcionada para crianças. Partimos do pressuposto de que é no interdiscurso que se constitui o jornalismo infantil da revista. Primeiramente, num estudo mais amplo e anterior a este, identificamos seis gêneros discursivos presentes na Recreio: o publicitário, o científico, o didático, o de entretenimento, o discurso sobre a própria revista e o jornalístico, considerado o primeiro. Neste estudo, utilizando conceitos da análise do discurso (AD) francesa, examinamos especialmente o discurso didático científico - na união desses dois gêneros - em sua aproximação com o jornalístico, trazendo o exemplo da análise de um texto.

Palavras-chave: jornalismo infantil; revista Recreio; discurso didático científico; interdiscurso.

\section{Abstract: The relationship between the didactic-Scientific and the journalistic discourses in Recreio magazine - We start from the premise that interdiscourse builds Recreio's magazine's journalism for children. In a previous study we have identified six discursive genres present in Recreio: the promotional, the scientific, the didactic and the entertainment discourses, the one about the magazine itself, and the journalistic, considered as the primary discourse. By using notions from the French Discourse Analysis, we examine the scientific didactic discourse, particularly - in the union of these two notions - in its approximation with the journalistic discourse, with an analysis of a text as an example.}

Keywords: journalism for children; Recreio magazine; scientific-didactic discourse; interdiscourse.

Este estudo ${ }^{1}$ propõe uma discussão sobre a construção do discurso do jornalismo infantil. O objeto da pesquisa é a revista Recreio, publicação brasileira direcionada para crianças. A publicação pertence à Editora Abril, maior grupo empresarial do mercado de revistas do país, e apresenta textos variados: explicações sobre animais, curiosidades

1 A pesquisa realizada neste estudo é um recorte de um trabalho mais amplo, elaborado a partir da tese de doutorado de uma das autoras, Thais Furtado, e de estudos realizados junto ao Núcleo de Pesquisa em Jornalismo (NUPJor). 
sobre temas científicos, piadas, cartas de leitores, temas comportamentais, etc. Partimos do pressuposto de que é na relação entre diferentes discursos, ou seja, no interdiscurso, que se constitui o jornalismo infantil da revista. Buscamos identificar quais os discursos presentes na Recreio além do discurso considerado primeiro, o jornalístico. Identificamos a presença de cinco: o publicitário, o científico, o didático, o de entretenimento e o que é feito sobre a própria revista.

Dentre esses gêneros discursivos citados, selecionamos para examinar neste artigo o didático e o científico em sua aproximação com o discurso jornalístico. Selecionamos um texto da revista que carrega consigo fortemente os sentidos didático e científico, mas também apresenta características próprias do discurso jornalístico. Ou seja, mostramos que estratégias próprias desses três gêneros são utilizadas na construção do discurso da revista infantil, sendo o jornalístico o primeiro (MAINGUENEAU, 2008). Por último, refletimos sobre o que representa esse interdiscurso para a construção da linguagem da revista.

\section{A revista Recreio}

A revista Recreio foi criada em 1969 e circulou em território nacional até 1981. Depois de um período fora de circulação, voltou a ser publicada em 2000, se mantendo em vendas até hoje. Com uma tiragem semanal média de $98.698^{2}$ exemplares em 2010, a Recreio atinge crianças na faixa entre seis e onze anos. Sua venda em bancas é maior do que por assinatura ${ }^{3}$. A revista é lida por crianças das classes A, B e $C^{4}$. Única publicação semanal brasileira voltada para o público infantil, ela vem sempre acompanhada por um brinquedo. A partir de março de 2000, a revista começou a distribuir coleções gratuitas de brinde junto da publicação, sendo esse um dos principais motivos de seu sucesso. Cada coleção de brinquedos leva em torno de 20 edições para ser completada.

A Recreio, no período desta pesquisa, nas regiões Sudeste e Sul, apresentava a coleção de brinquedos denominada Insectron e trazia também, em cada edição, algumas páginas de uma pequena enciclopédia colecionável sobre insetos e outros artrópodes. É comum que cada coleção seja acompanhada de parte de um colecionável de diferentes temas. Destacamos esse fato por percebermos que a própria coleção de brinquedos, no período estudado, estabelecia uma relação com os discursos didático e científico, que serão aqui examinados. O colecionável e os brinquedos distribuídos nesse período estimulavam o conhecimento e o aprendizado sobre os insetos - embora estimulem também o desejo de consumo.

2 Disponível em: <IVC/ www.aner.org.br>. Acesso em 03 de fev. de 2012.

3 Em março de 2011, a tiragem da revista foi de 113.380 exemplares, a circulação líquida de 75.627, sendo 25.188 por assinatura e 50.439 por venda avulsa. Disponível em: <www.publiabril.com.br $>$. Acesso em 03 de fev. de 2012.

4 De acordo com o portal Publiabril, os leitores da revista são divididos nas seguintes classes sociais: $38 \%$ classe A, $40 \%$ classe B, 22\% classe C. Disponível em: <http://www.publiabril.com.br/marcas-e-plataformas $>$. Acesso em 03 de fev. de 2012. 
Para a compreensão do processo de produção da revista, entrevistamos a diretora de redação, na época, Fernanda Santos ${ }^{5}$, que exercia a função desde janeiro de 2011. De acordo com ela, as reuniões de pauta eram realizadas às terças-feiras pela manhã. Nas tardes de terça, uma nova reunião era realizada para discutir apenas a "parte visual" da revista, como ela chamava. A diretora explica que os repórteres faziam as matérias na rua, mas há também "pautas frias", que são realizadas dentro da redação. Ela destaca o chamado "Painel de Crianças", composto por cerca de 300 crianças inscritas no site da revista que opinavam sobre o conteúdo da publicação. A cada mês, a equipe de Recreio fazia uma reunião presencial com essas crianças. Na segunda-feira acontecia o fechamento, dia em que a produção total da publicação era concluída e enviada para impressão na gráfica.

Feita a entrevista com a profissional, para compreensão das rotinas, no mapeamento do objeto foi possível estabelecer relações que aproximavam o jornalismo, a teoria construcionista e a análise do discurso. Utilizamos, posteriormente, para a análise, principalmente, a noção de interdiscurso.

\section{Jornalismo e análise do discurso}

Partimos do princípio de que o jornalismo é um discurso, como diz Benetti (2008), é um gênero discursivo com características próprias. Existem várias definições e abordagens para gênero. Benetti (2008) lembra que, em geral, entre os autores que pesquisam o jornalismo, os pontos de vista mais comuns nessa discussão são o funcional - que trata dos gêneros informativo, opinativo e, às vezes, interpretativo - e o textual - quando trata os gêneros a partir das características dos textos, dividindo-os entre notícia, reportagem, editorial, entre outros.

Para a autora, esses pontos de vista não "contemplam as relações intersubjetivas e de poder que efetivamente constituem um gênero" (BENETTI, 2008, p.15). Ela considera mais adequada uma abordagem comunicacional para tratar dos gêneros do discurso, ou seja, que ultrapasse a noção de texto. Isso porque o ponto de vista comunicacional torna possível a relação com as condições de produção específicas, assim como as condições de circulação e interpretação. Para analisar as produções jornalísticas de forma que se ultrapasse, então, a noção de texto, a análise do discurso francesa (AD) se mostra bastante adequada.

É possível perceber que a AD está em sintonia com a teoria construcionista, pois ambas levam em conta a exterioridade e a subjetividade, ou seja, a relação do sentido com o sujeito. "A vida cotidiana apresenta-se como uma realidade interpretada pelos homens e subjetivamente dotada de sentido para eles na medida em que forma um mundo coerente" (BERGER; LUCKMANN, 2009, p.35). O jornalismo é um modo de conhecimento.

5 Fernanda Santos concedeu entrevista especialmente para esta pesquisa, no dia 03 de agosto de 2011, na redação da revista Recreio, em São Paulo. Atualmente, não faz mais parte da equipe da revista. 
O discurso jornalístico possui características próprias que possibilitam a produção de um conhecimento particular sobre o mundo e ao mesmo tempo incorpora conhecimentos de outras áreas, de outros discursos. É justamente essa relação, esse interdiscurso, que acaba por caracterizar o discurso jornalístico.

Com isso, consideramos que o discurso da Recreio - formado por um interdiscurso específico - produz e oferece às crianças leitoras um conhecimento particular sobre os fatos do mundo. Estudar como se dá esse interdiscurso é uma forma de perceber como essa construção vem sendo feita, ou seja, de compreender como os discursos externos ao discurso jornalístico específico das revista são atualizados na rotina de Recreio, direcionada aos futuros leitores adultos.

\section{O interdiscurso}

Considerando que a análise do discurso francesa propõe que o discurso tem uma relação intrínseca com sua exterioridade, que o constitui, ele pode ser visto como incompleto, com falhas constitutivas. Benetti (2007) explica que o texto é decorrência de um movimento de forças que lhe é exterior e anterior. "O texto é a parte visível ou material de um processo altamente complexo que inicia em outro lugar: na sociedade, na cultura, na ideologia, no imaginário" (BENETTI, 2007, p.111). Sendo assim, as condições de produção de um discurso são tão importantes para a AD francesa e por isso foi importante conhecer a redação da revista Recreio para realizar este estudo.

Orlandi (2000) explica que, em relação às condições de produção de um discurso, pode-se considerar tanto o contexto imediato quanto o contexto amplo. No caso da revista Recreio, o contexto imediato é a redação, os jornalistas que trabalham na revista, o momento em que a publicação está sendo produzida, etc. O contexto amplo é o que traz para o discurso sentidos presentes na sociedade, na história e também mobilizam a memória. Ambos são importantes para a construção do discurso e são externos a ele. Cabe ao analista perceber que existe uma camada visível (o texto) e outra camada discursiva, determinada histórica e ideologicamente, e que só pode ser percebida através da análise.

A linguagem é sempre dialógica (BAKTHIN, 1979). Benetti (2007) explica que o dialogismo pode ser pensado em dois planos, que interessam particularmente ao jornalismo: o da relação entre discursos e o da relação entre sujeitos. O interdiscurso diz respeito ao primeiro plano, ou seja, o da relação entre os discursos, e está associado aos estudos de sentido, que é o caso deste trabalho. Pensar na relação entre discursos significa pensar na heterogeneidade discursiva.

A questão da heterogeneidade foi bastante discutida pela autora Jaqueline Authier-Revuz (1990, p.26), que afirma que "as palavras são, sempre e inevitavelmente, 'as palavras dos outros'". Ao considerar a questão sob a perspectiva da psicanálise, ela chega à conclusão de que "sempre sob as palavras, 'outras palavras são ditas'" (1990, p.28). Authier-Revuz baseia seus estudos em Bakhtin, partindo da premissa doautor deque a fala não é um ato individual, ou seja, nunca é neutra. 
Partindo do dialogismo, Bakhtin elaborou a teoria da polifonia, que se baseia na lógica de que várias vozes falam simultaneamente num mesmo texto. A partir dessas reflexões, Authier-Revuz passou a distinguir dois tipos de heterogeneidade: a heterogeneidade mostrada, que indica a presença do outro no discurso do locutor; e a heterogeneidade constitutiva, que consiste em uma "modalidade implícita que esgota a possibilidade de captar lingüisticamente a presença diluída do outro no um" (AUTHIER-REVUZ, 1990, p.32). Para a autora, a heterogeneidade é sempre constitutiva do discurso, mas quando não é mostrada, não é analisável.

Para Authier-Revuz (1990), a heterogeneidade mostrada pode apresentar-se em duas formas: marcada e não-marcada. Em sua forma marcada, ela é da ordem da sintaxe, enquanto a heterogeneidade constitutiva está ligada à ilusão-esquecimento número 1, proposta por Pêcheux $(1995)^{6}$, que faz com que o sujeito do discurso tenha a ilusão de ser a fonte, a origem, de seu dizer. Segundo Indursky (1997, p.40), a heterogeneidade mostrada em sua forma marcada é vista na materialidade linguística (discurso direto, discurso indireto, aspas). Já a modalidade não-marcada é da ordem do discurso, ela não é visível na materialidade linguística. Exemplos seriam o discurso indireto livre, a ironia, a metáfora, o jogo de palavras.

Maingueneau (2008) traz outro olhar para a questão da heterogeneidade discursiva. Ele lembra a proposta de Authier-Revuz (1990), mas cria sua hipótese sobre o tema: "Nossa própria hipótese do primado do interdiscurso inscreve-se nessa perspectiva de uma heterogeneidade constitutiva, que amarra, em uma relação inextricável, o Mesmo do discurso e seu Outro" (MAINGUENEAU, 2008, p.31).

Para explicar o que compreende sobre interdiscurso, Maingueneau (2008) substitui o termo por uma tríade: universo discursivo, campo discursivo e espaço discursivo. Para o autor, universo discursivo é o conjunto de formações discursivas de todos os tipos que interagem numa conjuntura dada. Ele explica que se trata de um conjunto finito, mas de pouca utilidade para o analista. O universo discursivo apenas define uma extensão máxima de sentidos a partir da qual serão construídos os campos discursivos que serão estudados.

Campo discursivo é definido pelo autor como "um conjunto de formações discursivas que se encontram em concorrência, delimitam-se reciprocamente em região determinada do universo discursivo" (MAINGUENEAU, 2008, p.34). Quando fala de concorrência, Maingueneau não está considerando apenas sentidos contrastantes. Para ele, concorrência significa tanto o confronto, quanto a aliança, ou seja, são discursos que se relacionam e possuem a mesma função social. Só divergem pelo modo como essa função social será desempenhada. A delimitação desses campos não é óbvia. Cabe ao analista fazer escolhas.

No caso do estudo aqui proposto, pode-se pensar no discurso da mídia (como um todo) como o universo discursivo, e o discurso do jornalismo infantil - especificamente

6 Segundo Pêcheux (1995), é possível distinguir duas formas de esquecimento no discurso. O esquecimento número dois é da ordem da enunciação. Ao falarmos, o fazemos sempre de uma forma e não de outra, mas temos a ilusão que aquilo que falamos só poderia ser dito com aquelas palavras e não com outras. 
o presente na Recreio - como o campo discursivo de interesse. "É no interior do campo discursivo que se constitui um discurso, e levantamos a hipótese de que essa constituição pode deixar-se descrever em termos de operações regulares sobre formações discursivas já existentes" (MAINGUENEAU, 2008, p.34). Esse campo é formado por diversos discursos, por isso ele é considerado heterogêneo. Todos se relacionam, e esses discursos podem se colocar em hierarquia, podendo uns se sobressaírem sobre os outros, mas não de forma estanque, considerando que o poder é circular.

É a partir daí que se definem os espaços discursivos, ou seja, subconjuntos de formações discursivas que o analista irá encontrar diante de seu problema de pesquisa. Por meio desses espaços discursivos e de suas relações que um discurso é caracterizado. Pensar a heterogeneidade discursiva dessa forma é considerar que a presença do interdiscurso está no próprio coração do intradiscurso, que são os sentidos relacionados e presentes no próprio discurso, ou no texto. Orlandi (2000) diz que, compreendendo o interdiscurso dessa forma, se entende que a exterioridade se inscreve no interior da textualidade. Para ela, "interdiscurso é todo o conjunto de formulações feitas e já esquecidas que determinam o que dizemos. Para que minhas palavras tenham sentido é preciso que elas já façam sentido" (ORLANDI, 2000, p.33).

Maingueneau (2008) fala de espaços discursivos que podem ser encontrados dentro de um campo discursivo. Além disso, o autor diz que não é possível dissociar um discurso primeiro de outros. "O discurso primeiro não permite a constituição de discursos segundos sem ser por eles ameaçado em seus próprios fundamentos" (MAINGUENEAU, 2008, p.39). Isso significa que se pode considerar que um discurso, então, é formado pela relação entre vários discursos, mesmo que um seja naquele momento dominante. Não seria diferente no caso do discurso jornalístico. Na revista Recreio, podemos dizer que existe um discurso "primeiro", como diz Maingueneau (2008), que é o discurso jornalístico (com suas características próprias), justamente por se tratar de uma publicação jornalística, com condições de produção específicas. Mas esse discurso também é formado por outros discursos, o que o torna heterogêneo como qualquer outro.

Ao fazer leituras periódicas da Recreio, percebemos nas páginas construídas pelos jornalistas a existência, entre outros já citados, de dois discursos externos que estão próximos ao jornalístico e que estão presentes em uma reflexão de Charaudeau (2009). O autor compara o discurso jornalístico ${ }^{7}$ com o científico e o didático, embora não faça nenhuma reflexão sobre os discursos direcionados às crianças.

Entre o discurso científico e o jornalístico existe em comum a problemática da prova, como propõe Charaudeau (2009). O primeiro, no entanto, exige uma demonstração racional, enquanto que, no segundo, a prova é da ordem da constatação, do testemunho, do relato dos fatos. No discurso científico, supõe-se que o destinatário já seja interessado

7 Charaudeau (2009), na verdade, denomina o discurso noticioso como "discurso informativo", mas optamos por utilizar o termo "discurso jornalístico", considerando as suas especificidades. 
previamente no tema tratado, enquanto que, no jornalístico, deve-se levar em conta a dissimetria entre o informador e o informado.

O discurso didático e o jornalístico se aproximam na atividade da explicação. "Não há uma explicação demonstrativa, como a que se encontraria numa obra científica, mas uma explicação explicitante" (CHARAUDEAU, 2009, p.62). Esses dois discursos têm alvos bastante amplos e não especializados, por isso não precisam revelar de maneira complexa uma verdade, mas apenas colocá-la em evidência de forma que se torne simplificada e compreensível. Essa atividade é chamada por Charaudeau de vulgarização.

Na observação empírica do objeto, percebemos a proximidade entre os discursos didático e científico. É difícil separar, em alguns textos da revista, a demonstração - própria do discurso científico -, da explicação, característica do discurso didático. Portanto, o discurso denominado por nós de didático científico se caracteriza por apresentar tanto o sentido da demonstração racional, que leva à prova a partir de um saber especializado, quanto o da explicação simplificada para um público amplo.

Nos discursos construídos a partir de explicações de fontes especializadas, por exemplo, não há normalmente uma demonstração que prove aquilo que está sendo dito. Existe, nos textos que tratam, por exemplo, de corpo humano, animais, geografia, muito mais a explicação simplificada do que a demonstração da prova, o que poderia nos levar a chamar esse tipo de discurso externo, perceptível na revista, apenas de didático. Como, no entanto, muitos dos assuntos tratados são aqueles que o senso comum considera como científicos (por exemplo, de fenômenos físicos, químicos ou biológicos) e há ainda textos em que a revista propõe experiências aos leitores, que levarão, então, à demonstração da prova, consideramos mais adequado manter duas denominações em um mesmo espaço discursivo. Portanto, por isso, nomeamos, para fins de análise, especificamente esse discurso externo presente na revista de discurso didático científico (DDC).

Com base nas considerações de Maingueneau (2008), é possível dizer que, entre os discursos, na Recreio, o discurso jornalístico (DJ) é o primeiro. O sentido dominante do DJ é o do status da verdade e da ordem do que já foi, tendo como modelo a credibilidade. Os sentidos no DJ são construídos a partir de provas testemunhais, da constatação e do relato dos fatos. A explicação é simplificada e dramatizada, já que atende um alvo amplo. O objetivo é transmitir um saber.

Todos os textos da revista Recreio buscam estabelecer um diálogo direto com o leitor e transmitir-lhe um saber. Todos, de alguma forma, trazem informações, novidades ou fatos fora do comum. São também próximos do leitor. Ou seja, vários critérios de noticiabilidade - como poderá ser visto na análise - são respeitados na escolha dos temas tratados pela Recreio. Portanto, é possível afirmar que todos os textos podem ser caracterizados como jornalíticos. Até porque são construídos a partir de uma lógica jornalística, dentro de uma rotina jornalística - feito por jornalistas, com utilização de pautas discutidas em reuniões, com entrevistas, pesquisas, etc. Cabe reforçar que, para Charaudeau (2009), o discurso 
jornalístico tem um alvo imaginado e definido e uma lógica comercial. A partir dessa lógica, ele procura se aproximar de seu alvo para captar mais público, que é o caso da Recreio.

O discurso da Recreio, com exceção do encontrado nos anúncios, é, portanto, jornalístico. Entretanto, a interdiscursividade existe e nem sempre as características apontadas por Charaudeau (2009) - e por diversos outros autores - para o discurso jornalístico são as que mais se destacam nos textos da Recreio. Além disso, não há normalmente na revista, como disse a diretora de redação Fernanda Santos (2011), textos com lead, técnica básica de redação jornalística. O discurso jornalístico presente na revista está sempre atravessado por outros. Muitas vezes, as características primordiais desses outros discursos se sobressaem. Em outras publicações, para públicos diferentes, certamente são outros interdiscursos que ocorrem.

Interessa destacar, neste artigo, especificamente, a relação entre o discurso didático científico e o discurso jornalístico na publicação direcionada às crianças, que serão os futuros leitores adultos. Isso será visto na análise que segue.

\section{A análise}

Definimos como textos em que os sentidos do discurso didático científico (DDC) predominam na Recreio, aqueles sobre história, corpo humano, ciências, lugares, animais, etc. Nas páginas que tratam desses temas, normalmente há fotos ou infográficos explicativos (de funções do corpo humano, por exemplo), ou mapas e fotos de lugares, ou ainda, quadros com dados e características daquilo que está sendo tratado. Para construir esses textos, na maioria das vezes, os jornalistas da revista consultam especialistas que têm seus nomes apresentados ao pé da página e não dentro do texto. A diretora de redação Fernanda Santos (2011), afirmou que os pais precisavam perceber que há valor agregado na revista, além do brinquedo e das páginas de entretenimento, para tomarem a decisão de comprar a publicação. Isso justifica, em parte, a inclusão de temas didático-científicos na revista, inclusive na capa.

Para fazer a análise da revista foram selecionadas, na tese que originou este estudo, um total de 1020 páginas que compõem as 23 revistas do corpus. O primeiro passo da análise foi identificar os diferentes discursos nas páginas da Recreio. O segundo foi separar sequências discursivas que exemplificassem o discurso predominante, para, em seguida, mostrar o interdiscurso dele com outros.

Escolhemos a matéria Um lixão Celeste (página 24 e 25, edição 606) para exemplificar um texto com a predominância dos sentidos do discurso didático científico (DDC): 


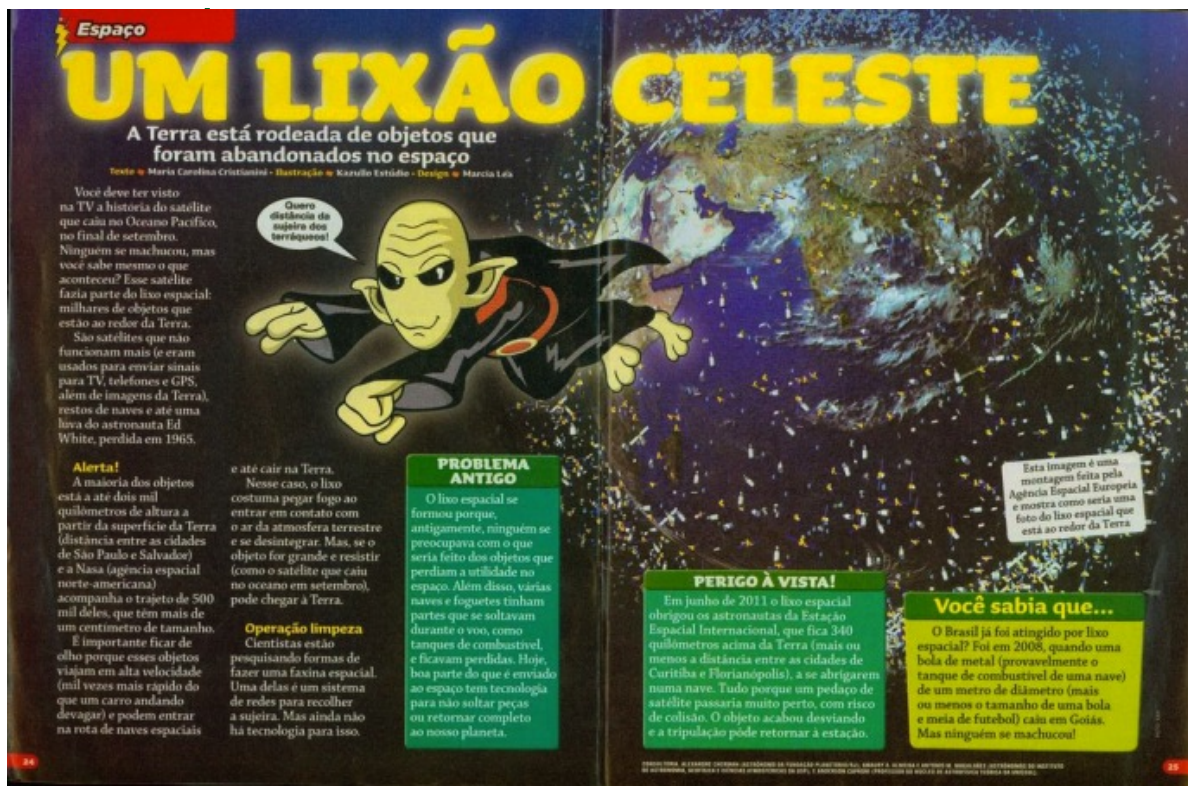

Fig. 1. Exemplo de análise.

- Sequência Discursiva 1 (SD1): Um lixão celeste - A terra está rodeada de objetos que foram abandonados no espaço

- Sequência Discursiva 2 (SD2): Você deve ter visto na TV a história do satélite que caiu no Oceano Pacífico, no final de setembro. Ninguém se machucou, mas você sabe mesmo o que aconteceu? Este satélite fazia parte do lixo espacial: milhares de objetos que estão ao redor da Terra.

- Sequência Discursiva 3 (SD3): A maioria dos objetos está a até dois mil quilômetros de altura a partir da superfície da Terra (distância entre as cidades de São Paulo e Salvador) e a Nasa (agência espacial norte-americana) acompanha o trajeto de 500 mil deles, que têm mais de um centímetro de tamanho. É importante ficar de olho porque esses objetos viajam em alta velocidade (mil vezes mais rápido do que um carro andando devagar) e podem entrar na rota de naves espaciais e até cair na Terra.

- Sequência Discursiva 4 (SD4): O lixo espacial se formou porque, antigamente, ninguém se preocupava com o que seria feito dos objetos que perdiam a utilidade no espaço. Além disso, várias naves e foguetes tinham partes que se soltavam durante o vôo, como tanques de combustível, e ficavam perdidas. Hoje, boa parte do que é enviado ao espaço tem tecnologia para não soltar peças e retornar completo ao nosso planeta. 
- Sequência Discursiva 5 (SD5): Você sabia que... O Brasil já foi atingido por lixo espacial? Foi em 2008, quando uma bola de metal (provavelmente o tanque de combustível de uma nave) de um metro de diâmetro (mais ou menos o tamanho de uma bola e meia de futebol) caiu em Goiás. Mas ninguém se machucou!

- Sequência Discursiva 6 (SD6): Consultoria: Alexandre Cherman (astrônomo da Fundação Planetário (RJ); Amaury A. Almeida e Antônio M. Magalhães (astrônomos do Instituto de Astronomia, Geofísica e Ciências Atmosféricas da USP); e Anderson Caproni (professor do Núcleo de Astrofísica Teórica da UNICSUL).

O texto aborda o tema do lixo espacial, que pode ser enquadrado como didático científico, como fica claro no título e na linha de apoio da matéria (SD1). Todos os entrevistados são especialistas da área da astronomia e da astrofísica, como pode ser visto na SD6. São cientistas. Essas fontes, como é norma na revista, não são destacadas, ou seja, não aparecem no texto da reportagem. Elas estão presentes apenas no rodapé no final da matéria, em letras bem pequenas. Em entrevista, a diretora de redação Fernanda Santos afirmou (2011) que, na opinião dela, para a criança não importa quem foram os entrevistados. É a revista que fala, assumindo o papel de especialista.

As fontes foram entrevistadas pelos jornalistas, mas, ao não aparecerem na reportagem, não são valorizadas. Portanto, as fontes não são visíveis na forma de discurso direto, ou discurso indireto, que seriam, segundo Indursky (1997), exemplos da heterogeneidade mostrada em sua forma marcada, visível na materialidade linguística. A heterogeneidade discursiva joga com a diluição do outro no um. Esse outro pode ser percebido ou não. No caso deste texto, a voz dos especialistas é diluída. Só é possível identificar que existem outras vozes na reportagem sobre o lixo espacial por causa da SD6, que é mostrada graficamente com uma letra bem menor do que a do corpo da matéria. Se os cientistas foram consultados, suas vozes naturalmente estão presentes nas outras sequências destacadas, mas a criança leitora possivelmente não perceberá isso e, mesmo que compreendesse que algumas pessoas foram consultadas, não conseguiria identificar quem disse o quê. Para ela, é a revista quem fala.

Na SD2, é possível ver que a revista fala diretamente com o leitor, como é comum no jornalismo de revista. Nessa mesma sequência, fica evidente o gancho, ou seja, o que motivou a reportagem ("Você deve ter visto na TV a história do satélite que caiu no Oceano Pacífico, no final de setembro"). O fato de ter caído um satélite no Oceano Pacífico motivou a revista a publicar um texto sobre o lixo espacial, um tema científico. Fica clara, então, a relação do Discurso Didático Científico (DCC) com o Discurso Jornalístico (DJ), pois foi um acontecimento que provocou a publicação da matéria. De acordo com Charaudeau (2009), no DJ, o status da verdade é da ordem do que já foi: algo aconteceu e precisa ser conhecido. Nesse caso, um satélite caiu. Além disso, esse acontecimento também serviu 
de gancho para que a Recreio falasse de outro acontecimento ainda mais antigo, presente na SD5: a queda de uma bola de metal, em 2008, no Brasil.

Charaudeau (2009) também afirma, como foi dito, que o discurso científico e o discurso jornalístico têm em comum a problemática da prova. No caso do DJ, a prova é da ordem da constatação, do testemunho, do relato dos fatos. Um satélite caiu, e isso pode ser constatado. Já o discurso científico exige uma demonstração racional, o que é difícil de se fazer em um texto jornalístico. Mesmo assim, um fato concreto e já conhecido pode ser visto como uma prova racional.

Na SD4, a revista explica - característica do discurso jornalístico e do discurso didático - como o lixo espacial se formou e, na SD3, justifica o fato de um satélite ter caído. Para que o discurso se torne compreensível para as crianças - público-alvo (outro objetivo do discurso jornalístico e do discurso didático), a revista compara dados importantes para o entendimento do tema - como a distância que os objetos estão da Terra, a velocidade com que eles se movimentam, o tamanho de um objeto que já caiu sobre o Brasil - com situações ou objetos mais próximos da realidade das crianças. Isso acontece na SD3 ("distância entre as cidades de São Paulo e Salvador" / "mil vezes mais rápido do que um carro andando devagar") e na SD5 ("mais ou menos do tamanho de uma bola e meia de futebol").

Para Charaudeau (2009), o discurso jornalístico não pode pretender nem a cientificidade nem a didaticidade.

O discurso científico implica a seleção de um público muito reduzido, ultraespecializado, que possua os mesmos instrumentos de raciocínio, a mesma terminologia, e compartilhe os mesmos conhecimentos da comunidade científica em questão (CHARAUDEAU, 2009, p.76).

O autor diz que o jornalismo também não pode visar a um discurso perfeitamente didático, porque a organização do saber do discurso didático prevê provas de verificação e de avaliação do conhecimento, ao menos que se pense em uma didaticidade midiática diferente da escolar. Mas percebe-se, no entanto, que existe um forte interdiscurso entre o DDC e o DJ. O tema é da área científica, a forma de explicar o que aconteceu se assemelha ao discurso didático e a motivação da publicação foi um acontecimento de interesse jornalístico, que se enquadra em critérios de noticiabilidade, como proximidade, relevância, novidade, notabilidade e inesperado (TRAQUINA, 2008). Mas chama a atenção que a revista faz questão de destacar que ninguém se machucou com as quedas de lixo espacial, o que pode ser notado em SD2 e SD5, mostrando que o critério de noticiabilidade da morte (ou da possibilidade dessa) não é considerado adequado para o público da revista. 


\section{Considerações finais}

Percebemos que o discurso jornalístico de Recreio é formado pelos interdiscursos que o constituem, que pode ser diferente dos interdiscursos de outras publicações. É a partir desse interdiscurso que a revista produz e oferece às crianças um conhecimento particular sobre o mundo. Especificamente no recorte proposto, podemos constatar características próprias tanto do discurso didático científico quanto do discurso jornalístico, na matéria analisada. Esse interdiscurso, como afirma Maingueneau (2008), faz com que o discurso primeiro no caso do discurso jornalístico - ao permitir a constituição de discursos segundos - no caso o discurso didático científico -, fique ameaçado em seus próprios fundamentos.

Critérios de noticiabilidade e rotinas jornalísticas estão presentes na produção da revista e no texto analisado. São essas características que norteiam as pautas e conteúdos de Recreio, mas características como a explicação didática, por exemplo, acabam sendo úteis para fazer com que o discurso jornalístico se modifique e se aproxime mais de seu público-alvo, no caso, as crianças. Fica evidente também no texto analisado a presença da prova e da validação de conhecimentos, valorizada tanto no discurso jornalístico quanto no científico.

O ponto que merece maior destaque, no entanto, é o fato de as fontes (especialistas) não serem valorizadas, já que não aparecem no corpo da matéria. Isso chama atenção porque tanto para o discurso jornalístico quanto para o discurso científico as fontes são fundamentais. No caso da revista Recreio, a forma como o discurso é construído faz com que a própria revista ocupe o papel de expert. Ela assume o lugar do cientista, daquele que tem propriedade de falar sobre um tema complexo para a criança. Dessa forma, ela ao mesmo tempo se valoriza diante de seu público (buscando para si o status de especialista), e se aproxima de seu público, construindo um discurso jornalístico e didático acessível.

Cabe ressaltar, porém, que as crianças são leitores em formação e que, neste caso, o discurso jornalístico está abrindo mão de uma de suas principais características, que é a de deixar claro quais são as fontes de informação consultadas sobre o fato tratado. Essa reflexão se torna ainda mais importante no momento em que se consolidam novas formas de informação, na internet e especialmente nas redes sociais, distantes do jornalismo, em que as fontes não são valorizadas. Mesmo que cientistas sejam entrevistados pela revista, ao não tornar suas fontes visíveis na materialidade do texto, o jornalismo está abrindo mão para leitores futuros de uma das estratégias mais importantes de manutenção de seu maior valor: a credibilidade.

Thaís Helena Furtado é professora e coordenadora do Curso de Jornalismo do Campus de Porto Alegre e coordenadora da Agência Experimental de Comunicação (Agexcom), 
da Universidade do Vale do Rio dos Sinos - UNISINOS. Doutora em Comunicação e Informação (UFRGS). Membro do Núcleo de Pesquisa em Jornalismo (NUPJor).

thaisf@unisinos.br

Sabrina é professora do Curso de Jornalismo da Universidade do Vale do Rio dos Sinos (Campus Porto Alegre e São Leopoldo). Coordenadora Pedagógica do Curso de Especialização em Jornalismo Esportivo - FABICO/UFRGS. Doutora em Comunicação e Informação (UFRGS). Membro do Núcleo de Pesquisa em Jornalismo (NUPJor).

sabrinafranzoni@yahoo.com.br

\section{Referências}

AUTHIER-REVUZ, Jaqueline. Heterogeneidade(s) enunciativa(s). Cadernos de estudos lingüísticos. Campinas: n. 19. jul/dez., 1990.

BAKHTIN, Mikhail. Marxismo e filosofia da linguagem. São Paulo: Hucitec, 1979.

BENETTI, Marcia. O jornalismo como gênero discursivo. Galáxia. N. 15. São Paulo: PUC-SP, 2008.

Análise do discurso em jornalismo: estudo de vozes e sentidos. In: LAGO, Cláudia; BENETTI, Marcia (org.). Metodologia de pesquisa em jornalismo. Petrópolis: Vozes, 2007.

BERGER, Peter; LUCKMANN, Thomas. A construção social da realidade. 30.ed. Petrópolis: Vozes, 2009.

CHARAUDEAU, Patrick. Discurso das mídias. São Paulo: Contexto, 2009.

INDURSKY, Freda. A fala dos quartéis e outras vozes. Campinas: Ed. Unicamp, 1997.

INSTITUTOVERIFICADOR DE CIRCULAÇÃO (IVC) [site] Disponível em: <www.aner.org.br> Acesso em 22 de janeiro de 2012.

MAINGUENEAU, Dominique. Gênese dos discursos. São Paulo: Parábola Editorial, 2008.

ORLANDI, Eni. Análise de discurso: princípios e procedimentos. Campinas: Pontes, 2000.

PÊCHEUX, Michel. Semântica e discurso: uma crítica à afirmação do óbvio. 2.ed. Campinas: Ed. Unicamp, 1995.

TRAQUINA, Nelson. Teorias do jornalismo: a tribo jornalística. V. 2. Florianópolis: Insular, 2008. 